\title{
Género, ciudad y violencia(s). Territorialidades y cartografías emergentes
}

\section{Gender, city, and violence(s). Emerging territorialities and cartographies}

\author{
Natalia Czytajlo*
}

Citar este artículo como: Czytajlo, N. (2020). Género, ciudad y violencia(s). Territorialidades y cartografías emergentes. Revista Nodo, 14(28), pp. 41-57.

\section{Resumen}

Dos procesos paradojales concurren en las ciudades de América Latina ante el avance neoliberal en la región: por un lado, las violencias que se expresan particularmente sobre el cuerpo de las mujeres y los cuerpos disidentes y por otro, las expresiones de sujetos emergentes, en particular del movimiento de mujeres, en el espacio público.

El presente trabajo indaga en las relaciones entre las dimensiones simbólico-representativa y material-física de las construcciones de género y la(s) violencia(s) en el espacio público de la ciudad. Incorpora el análisis de iniciativas en el espacio metropolitano de Tucumán.

Los resultados presentados devienen de una estrategia de trabajo desarrollada en un espacio de experimentación universitaria vinculado a la temática del género y el urbanismo. Se utilizan enfoques y métodos del urbanismo, la antropología, la geografía. En particular se adopta la cartografía social como herramienta interpretativa e instrumento para la acción por el derecho a la ciudad.

Palabras clave: desigualdades, espacio público, género, ciudad.

\section{Abstract}

Two paradoxical processes concur in the cities of Latin America before the neoliberal advance in the region: on the one hand, the violence that is expressed particularly on the body of women and the dissident bodies and on the other, the expressions of emerging subjects, in particular of movement of women, in the public space. The present work investigates the relations between the symbolic-representative and material physical dimensions of gender constructions and violence(s) in the public space of the city. The analysis of initiatives in the metropolitan area of Tucumán is incorporated. The results presented come from a work strategy developed in a space of university experimentation of gender and urban planning. Methodological approaches to urban planning, anthropology, geography are used. In particular, social cartography is adopted as an interpretive tool and instrument for action for the right to the city.

Keywords: inequalities, public space, gender, city.

Fecha de recepción: 14 de junio de 2019 • Fecha de aceptación: 9 de enero de 2020

\footnotetext{
* Arquitecta y doctora en Ciencias sociales, especialista en estudios de las mujeres y de género CONICET - UNT, Observatorio de Fenómenos Urbanos y Territoriales. Facultad de Arquitectura y Urbanismo, Universidad Nacional de Tucumán. Correo electrónico: nczytajlo@gmail.com
} 


\section{Introducción: puntos de partida}

La desigualdad, asumida como matriz de las violencias, representa un rasgo estructural $y$ por tanto un desafío fundamental para América Latina y demanda innovadores marcos conceptuales, analíticos e interpretativos. El estudio sobre la(s) desigualdad(es) ocupa un lugar relevante en los aportes académicos recientes desde miradas que suponen privilegiar categorías generalmente omitidas, superando un foco tradicional que prioriza las desigualdades de ingresos. El espacio urbano también se analiza vinculado a esa (re) producción de la desigualdad social en las ciudades latinoamericanas (Segura, 2014).

Por otra parte, cada vez con mayor frecuencia, el género se sitúa como categoría analítica útil para evidenciar desigualdades. Ello, desde su definición como construcción social, histórica, cultural, simbólica y forma en que la sociedad organiza las relaciones de poder (Scott, 1986 cit. Czytajlo, 2013). Como tal, permite visibilizar las diferencias entre mujeres y varones, no desde un punto de vista binario, sino porque explicitar las diferencias y la subordinación de las mujeres en relación a los varones, también permite visibilizar a otros colectivos omitidos, LGBTIQ+, en interseccionalidad con otras categorías (Falú, 2016).

El género como herramienta política permite además comprender la construcción de las identidades, los marcos de los procesos sociales donde las desigualdades e injusticias territoriales y espaciales se construyen y en tal sentido, cuestiona la preeminencia de unos sobre otras.

El abordaje de la articulación género y espacio supone el análisis de diferentes elementos donde se cruzan dimensiones y esferas: i) una esfera material, que implica, a partir de la lectura de la interseccionalidad ${ }^{1}$, visibilizar las desigualdades de acceso a los activos y oportunidades de la vida en la ciudad; ii) una esfera simbólica, que desentraña los

1 Asumida como perspectiva útil para analizar la forma en que interactúan las múltiples opresiones en mujeres. sistemas y construcciones discursivas, las representaciones sociales sobre la identidad de género; iii) una esfera política, que analiza las relaciones de poder, de dominación y resistencia y la apropiación de diferentes sujetos, la(s) territorialidad(es) (Czytajlo, 2013) ${ }^{2}$.

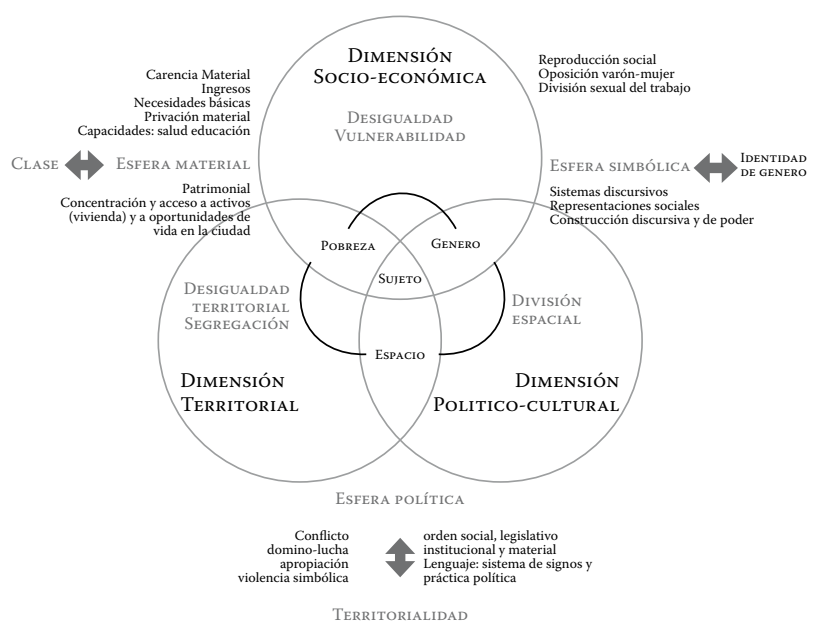

Figura 1. Esquema conceptual articulación categorías. Fuente: elaboración propia (2013).

Segato (2018) nos interpela a no guetificar la cuestión de género, a no considerarla fuera de su contexto histórico, sólo como una relación entre hombres y mujeres, sino como el modo en que esas relaciones se producen en el contexto de sus circunstancias históricas. No guetificar la violencia de género también quiere decir que su carácter enigmático se esfuma y la violencia deja de ser un misterio cuando ella se ilumina desde la actualidad del mundo en que vivimos. Según esta autora, aunque se observan de forma fragmentada, como casos dispersos de letalidad de las mujeres -cada vez más frecuentes-, son epifenómenos que parten de circunstancias plenamente históricas de las relaciones sociales. Por ello, parte sustantiva de este artículo se centrará en vincular el contexto

2 Este artículo asume una propuesta teórico-metodológica que surge a partir de la revisión exhaustiva de aportes y referentes temáticos. Cabe señalar Falú, 1999; Lamas, 2000; McDowell, 2000; Sánchez de Madariaga, 2004; Vargas, 1996; Saborido, 1999, entre otras (Czytajlo, 2013). 
de las desigualdades urbanas y las violencias, así como también los modos en que estos temas se incorporan en la agenda pública.

Por otra parte, en este trabajo asumimos el espacio como espacio social, producto de la acción humana, no objeto dado ni preexistente a la misma, sino producido socialmente e históricamente, como objeto a ser indagado en el marco de los procesos sociales que lo involucran (Romero, 2004). Nos centramos además en el abordaje del espacio público de la ciudad. Este espacio social responde a la condición de clase, que conforma el espacio material; pero se relaciona también con el mundo del sujeto, la autonomía de los agentes individuales y sociales en los procesos de reproducción social, dimensiones de la identidad personal y social. La construcción de territorialidad implica considerar al espacio geográfico como un espacio social en permanente y acelerada transformación, dinámico, cambiante, en relación con el dinamismo y con los cambios sociales que tienen lugar y los procesos de apropiación (Romero, op.cit.). En ese sentido la tesis sostenida por la antropóloga Teresa del Valle (1997) supone una interpretación dinámica del enfoque de los criterios de género en evolución que nos lleva al proceso de cambio espacial.

De otro lado, según María Ángeles Durán (2008) la mayor parte de lo que se ha escrito sobre las ciudades se ha hecho prescindiendo del análisis del sujeto que producía el conocimiento, dándose por sentado que este era un sujeto cognoscente universal, transparente y puro. De alguna manera, este sujeto se las arreglaba para encarnar una sabiduría o una capacidad de conocer incontaminada de sus rasgos personales. Por eso, la toma de la palabra por aquellos colectivos que históricamente han estado excluidos del acceso a la producción sistemática de conocimiento no puede quedar limitada a las fichas de matrícula o a una simple ocupación de los puestos docentes. Afecta también a la crítica del sujeto cognoscente anterior, que pierde su cobertura de representante universal en la producción del conocimiento y se hace muy visible en sus perfiles personales y sociales.

\section{Aspectos metodológicos}

Este artículo recoge aportes de proyectos sobre el caso del sistema metropolitano de Tucumán (SiMeT) desde la perspectiva del "derecho a la ciudad"3 que se asume como concepto analítico que permite evaluar la evolución de las directivas urbanas pero también como concepto político para promover alternativas que surgen de procesos de movilización social junto a los de reflexión intelectual (Cuenya, 2012). Se plantea en el marco de una trayectoria de trabajo sobre género y hábitat y de una estrategia colectiva en un ámbito académico de la disciplina de urbanismo. Lo anterior implica la articulación de actividades de investigación, docencia y extensión desarrollados entre 2018 y 2019 desde un espacio de experimentación universitaria: el Laboratorio de género y urbanismo ${ }^{4}$. La experiencia articula aproximaciones y avances de investigaciones y tesis doctorales, así como asignaturas electivas en la carrera de Arquitectura con participación de alumnas de la Facultad de Arquitectura y Urbanismo.

Considerando el género y territorio como resultado de un complejo proceso de construcción social (Peña Molina, 1998); lo cualitativo, constituye una aproximación metodológica. Privilegiar el empleo de la metodología cualitativa, ha implicado la recuperación, por medio de la palabra, de las experiencias de las mujeres, teniendo como

3 Proyectos en curso en el Observatorio de Fenómenos Urbanos y Territoriales. Cabe mencionar PICT 2027/ 2016: Desafíos metropolitanos de Tucumán: Instrumentos para un nuevo programa urbano. Inv. Resp. M. Casares- Grupo Resp. N. Czytajlo, B. Garrido/ Programa PIUNT B 618 Programa Metropolitano de Tucumán 2030 / Proyecto Laboratorio de Género y Urbanismo / Proyecto de Extensión: Género, ciudad y violencias en articulación con la Secretaría de la Mujer, del Gobierno de la Provincia de Tucumán. Dirección: N. Czytajlo. Participantes: Alumnas FAU: Yubalena Grimaldos (becaria), Virginia Soria Mansilla (PPA), Sofía Ordoñez (PPA), Jazmín López (Tesista doctoral).

$4 \quad$ Las actividades desarrolladas pueden seguirse en [http:// www.observatoriofau.org/?p=53]. [https://www.facebook.com/ groups/261137021064227/]. 
uno de los principales propósitos, observar los signos de las construcciones conceptuales, así como las interpretaciones e interacciones de los grupos humanos.

El espacio social subjetivo, supone la consideración de los discursos y las prácticas de la representación del espacio por parte de individuos y grupos sociales. Las geografías feministas han mostrado hasta qué punto el espacio transmite símbolos, se presenta como símbolos y ordena patrones simbólicos de incidencia social (McDowell, 2000).

El análisis cualitativo de la información relevante ha supuesto un proceso de selección con el objetivo de extraer los elementos más importantes. Se emplearon como herramientas de apoyo para el registro y la organización de la información, material gráfico y fotográfico. La información recogida y los datos recabados se interpretan en el contexto de ciertos supuestos teóricos, por lo que se ocupa de la realidad y de la relación entre las perspectivas de significado de las actoras y las circunstancias en las que éstas se encuentran; de ahí el seguimiento, registro e integración de información producida a partir de encuestas ad hoc online, la revisión de fuentes secundarias tales como medios locales online, observación participante, talleres y mapeos colaborativos desarrollados en la Facultad de Arquitectura y en espacios públicos de San Miguel de Tucumán en el marco de articulaciones interinstitucionales con organismos gubernamentales y no gubernamentales.

\section{El género y la violencia de género como tema de la política pública}

La temática de género atraviesa cada vez con más intensidad la agenda discursiva de los gobiernos y los organismos internacionales ${ }^{5}$. En toda América Latina, con la contribución del movimiento feminista, se ha avanzado en la construcción de una perspectiva propositiva centrada en la titularidad

5 Podemos distinguir sin embargo matices entre los países y períodos políticos en el período reciente. de derechos y la autonomía de las mujeres como base para la igualdad de género y el desarrollo sostenible (ILPES-CEPAL, 2016). La Agenda 2030 y los Objetivos de Desarrollo Sostenible (ODS), en particular el ODS $5^{6}$ y ODS $11^{7}$, representan al menos una renovada oportunidad de permear la agenda pública de una manera transversal ${ }^{8}$.

Otras agendas regionales enfatizan esta sinergia. La Estrategia de Montevideo -documento surgido de la XIII Conferencia Regional sobre la Mujer de América Latina y el Caribe $-{ }^{9}$ incluye acuerdos sobre los instrumentos y medios para avanzar hacia la garantía efectiva de esos derechos y la

6 ODS 5. Lograr la igualdad entre los géneros y empoderar a todas las mujeres y niñas.

7 ODS 11 . Conseguir que las ciudades y los asentamientos humanos sean inclusivos, seguros, resilientes y sostenibles.

8 En lo que respecta Tucumán, ya en 2006 el gobierno había suscrito a una serie de lineamientos internacionales respecto al seguimiento de los Objetivos de Desarrollo del Milenio, reconociendo el aporte de análisis de indicadores desagregados por sexo para indagar en las desigualdades de género. Sin embargo la tendencia ha sido el trabajo sectorial y no se han logrado respuestas transversales. Actualmente el Portal de los Lineamientos Estratégicos para la provincia para el desarrollo, recoge los avances en relación a los ODS: http:// led.tucuman.gob.ar/.

9 La agenda regional de género comprende los compromisos de los Gobiernos de América Latina y el Caribe con los derechos y la autonomía de las mujeres, y la igualdad de género, que se aprobaron en las reuniones de la Conferencia Regional sobre la Mujer de América Latina y el Caribe, desde la primera Conferencia Regional sobre la Integración de la Mujer al Desarrollo Económico y Social de América Latina (La Habana, 1977) hasta la actualidad, en los términos en que los Gobiernos de la región se sumaron a ellos, que constan en 40 años de agenda regional de género. Para el diseño de la Estrategia de Montevideo la Comisión Económica para América Latina y el Caribe (CEPAL), como Secretaría Técnica de la Conferencia Regional sobre la Mujer de América Latina y el Caribe, hizo una revisión sistemática del lenguaje acordado durante los casi 40 años de la agenda regional de género, que, tomando en consideración el contexto socioeconómico y los debates sobre los Objetivos de Desarrollo Sostenible con los Gobiernos de la región y la sociedad civil, permitió identificar los acuerdos vinculados a los diferentes ejes para la implementación. 
autonomía bajo los principios de igualdad y no discriminación.

Distintos acercamientos teóricos, así como organizaciones de derechos humanos vinculadas al Programa de las Naciones Unidas para los Asentamientos Humanos, cuya tercera conferencia Hábitat se realizara en 2016, agencias como ONU Mujeres y mecanismos regionales, tales como las cumbres iberoamericanas de agendas locales de género (Mujer y ciudad), dieron cuenta de que la inequitativa distribución del poder social, económico y político entre mujeres y varones, la división sexual del trabajo y de roles sociales, implican también distintas formas de vivir y percibir la ciudad, la movilidad, el uso de los espacios y servicios públicos, la seguridad, etc.

En Argentina un contexto de "revolución normativa" ${ }^{10}$ en los últimos veinte años, a partir de nuevas legislaciones, cambios jurídicos y culturales en lo relativo a derechos e igualdad social y de género, hace parte de un escenario dinámico en términos de reconocimiento de sujetos de derechos ${ }^{11}$ con fuerte implicancia de la lucha feminista y numerosas iniciativas directas e indirectas sostenidas en la agenda pública orientadas a la disminución de las desigualdades estructurales.

Respecto de la violencia, en el año 2009 la Ley 26.485 de Protección Integral para Prevenir, Sancionar y Erradicar la Violencia contra las

10 Así se refiere Luciana Peker (2019).

11 Desde la Ley de Cupo votado en 1991, Leyes de Salud Sexual y Procreación Responsable (2002), Parto Humanizado (2004), Educación Sexual Integral (2006), Acceso a la Ligadura de Trompas y Vasectomía (2006), Trata de personas (2008 - 2012), Ley de Identidad de Género y Matrimonio Igualitario en relación a acuerdos y pactos a los que nuestro país ha adherido y dado carácter jurídico, Fertilización Asistida Igualitaria (2013), Penalización del grooming o acoso sexual vía internet (2013), Trabajadoras de Casas Particulares (2013).

En Julio de 2018 se sancionó la Ley Brisa que fija una reparación económica a familiares de violencia de género y en diciembre 2018 la Ley Micaela García que reglamenta la capacitación en perspectiva de género y violencia.
Mujeres (Decreto Reglamentario 1011/2010), permite un salto cualitativo en materia legislativa ${ }^{12}$. Recientemente la ley nacional 27.501, incorpora una nueva dimensión la "violencia contra las mujeres en el espacio público", manifestada como aquella ejercida contra las mujeres por una o más personas en lugares públicos o de acceso público (medios de transporte, centros comerciales, etc.) a través de conductas o expresiones verbales o no verbales con connotación sexual que afecte o dañe su dignidad, integridad, libertad, libre circulación o permanencia y/o generen un ambiente hostil $u$ ofensivo.

Entre los hechos recientes durante el año 2018 Argentina experimenta la media sanción en diputados y la discusión en Senado del proyecto de Interrupción Voluntaria del Embarazo (IVE). La misma, fue asumida como una victoria política en tanto la discusión sobre el derecho a decidir sobre el propio cuerpo consiguió atravesar las fronteras parlamentarias para instalarse de lleno en la sociedad $^{13}$.

\section{Las desigualdades como forma de violencia}

Las siguientes líneas buscan dar cuenta de cómo este contexto de oportunidad comparte escenario con uno de naturalización de las desigualdades y la(s) violencia(s), construcción sociohistórica cuyas expresiones requieren ser desveladas en el territorio y la ciudad desde una perspectiva de género.

12 Incorporando los mandatos de la Convención Interamericana para Prevenir, Sancionar y Erradicar la Violencia contra la Mujer (1994) y lo pautado en por la Convención sobre la Eliminación de Todas las formas de discriminación contra la mujer (CEDAW) y sumado a la sanción de un nuevo Código Civil y Comercial de la Nación, así como, la promulgación del Código Procesal Penal de la Nación bajo Ley $\mathrm{N}^{\circ} 27.063$, que viene a disminuir los plazos en los procesos y otorgar mayor protagonismo a las víctimas.

13 Ver: https://www.perfil.com/noticias/politica/2019-vol veran-presentar-proyecto-legalizacion-aborto.phtml 
En la segunda década del siglo XXI, la desigualdad se instala como característica del modelo de estructuración metropolitana latinoamericana. Desde la esfera material, el proceso desigual de ocupación urbana en las ciudades latinoamericanas refleja una localización de equipamientos y servicios públicos en las áreas centrales, que facilita la accesibilidad de una parte de la población. Análisis previos (Czytajlo, 2017) muestran que aún en un escenario con políticas activas, el espacio metropolitano hace parte de un proceso donde la periferia asiste a un proceso de acumulación de desventajas económicas y sociales asociadas a asimetrías de poder, de clase y también de género ${ }^{14}$.

La vulnerabilidad se incrementa en el caso de las mujeres de grupos sociales con menor poder social y se evidencia en el territorio, con desigualdades de acceso a la propiedad y condiciones de vivienda, mercado laboral e ingresos (acceso a los recursos), y también con desigualdad de acceso a la ciudad, en tanto persisten mayores responsabilidades en el hogar -cuidado y tareas cotidianas- (Czytajlo, 2017).

El tiempo emerge también como variable de las desigualdades socioterritoriales de género. Según la Encuesta sobre trabajo remunerado y uso del tiempo desarrollada por INDEC (2014), como módulo de la Encuesta Anual de Hogares Urbanos (EAHU) para Argentina durante el tercer trimestre de 2013, el total nacional urbano de la tasa de participación femenina en el trabajo remunerado ronda en un porcentaje del $88,9 \%$ con un tiempo promedio dedicado por las mujeres al mismo de 6,4 horas. En la provincia de Tucumán el porcentaje de participación femenina ascendía a $93,4 \%$ y el promedio a 7,3 horas.

14 La evolución del Índice de Desarrollo en Género muestra un crecimiento significativo a partir del 2006 en el país $(0,810$ frente a 0,781 en 1996$)$ y en la provincia $(0,787$ frente a 0,756 en 1996), registra para el 2016 un leve ascenso respecto de 2011 en el país $(0,841)$ y una baja para Tucumán $(0,829)$ (Czytajlo, 2017).
Las exploraciones sobre el uso del tiempo en el caso metropolitano señalan valores similares. El tiempo promedio de las mujeres en quehaceres domésticos es de 3,69 (4,1 para la provincia de Tucumán), las horas dedicadas al apoyo escolar es de 1,88 y al cuidado de personas es de 7,5 (Czytajlo, 2017) ${ }^{15}$.

El desarrollo de actividades cotidianas o especiales, tales como el uso del transporte y los servicios, de salud, educación y cuidado, hacer deporte, actividades de recreación en plazas y espacios públicos, por mencionar solo algunas, supone mayores desigualdades de tiempo vinculadas también a la localización y servicios disponibles y a cómo se organiza la vida de unos y otras.

En el aglomerado metropolitano de Tucumán, en el período intercensal 2001-2010, se incrementaba el porcentaje de hogares con jefatura de hogar femenina, superando el promedio provincial. En sectores de la periferia un $26 \%$ de hogares contaba en ese entonces con jefatura femenina coincidiendo a su vez con menor cantidad y frecuencia de líneas de transporte público, bienes y servicios. Ello, considerando que los medios de movilidad mayormente utilizados por las mujeres son el transporte público y el traslado a pie, dificulta el acceso real a las ofertas urbanas y redunda en más limitaciones a la vida urbana (PTUMA, 2011). ${ }^{16}$

15 Cabe señalar que las horas consignadas para trabajo remunerado también alcanza las 8 horas y que el universo al que se aplicó la encuesta online desarrollada en julio de 2017 fue principalmente de mujeres universitarias y trabajadoras.

16 El PTUMA. Ciudades del interior fue el marco en el que se desarrolló un estudio para el Área Metropolitana de Tucumán en 2011. Estas dimensiones fueron exploradas en articulación con algunos análisis sobre Ciudad, género y juventud: Indicadores y desafíos urbanos para San Miguel de Tucumán (Almará Gussoni, Beca CIUNT, 2017- 2018). Actualmente nuevos desarrollos se encuentran en curso en el OFUT sobre Movilidad urbana y desigualdad socio-territorial, tesis de doctorado en ciencias sociales en elaboración. 

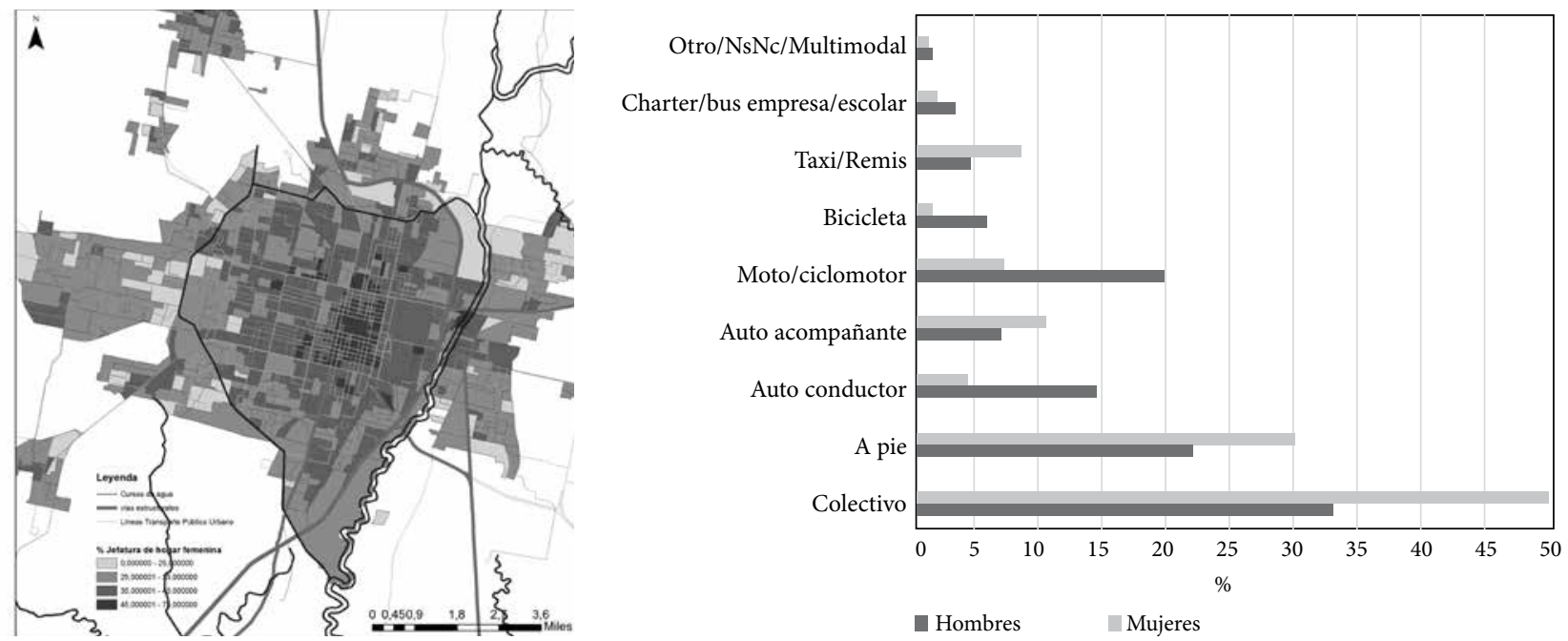

Figura 2. Desigualdades socioterritoriales de género en el aglomerado tucumano. Fuente: a) Czytajlo, 2019 y b) PTUMA EOD, 2011.

La exclusión no es solo material sino también subjetiva y simbólica. La literatura feminista señala que incorporar una mirada democrática de derechos en las ciudades requiere iluminar también, los procesos a través de los cuales funcionan las lógicas de la exclusión y subordinación, develando los mecanismos menos visibles, que son más impactantes por la naturalización con que funcionan.

La propuesta analítica de las desigualdades socio territoriales de género, desarrollada principalmente en la escala metropolitana (Czytajlo, 2013, 2017), asume dimensiones simbólicas e interaccionales que requiere de diversas escalas y aproximaciones.

El espacio produce identidad, y ésta se asienta en signos y símbolos por medio de los cuales los sujetos lo reconocen. Autores como Di Lullo (2009) aluden al espacio público como: i) espacio social definido mediante categorizaciones y acciones simbólicas; ii) expresión de relaciones de poder y conceptos de igualdad/desigualdad; iii) área física delimitable por las actividades, la gente que los ocupa, los elementos que lo contienen y los contenidos simbólicos; iv) espacio en el que se desarrollan las actividades sociales que influyen en ellas y son a la vez, producto de ellas; v) espacio continente y contenido.

El espacio público es también, según Borja (1999 citado en Di Lullo, 2009), el espacio principal del urbanismo, de la cultura urbana y de la ciudadanía. Es un espacio físico, simbólico y político. El espacio público es el de la representación, en el que la sociedad se hace visible. Del ágora a la plaza, de las manifestaciones políticas multitudinarias del siglo XX, es a partir de estos espacios que se puede relatar y comprender la historia de una ciudad.

Los espacios públicos refieren a los espacios de uso colectivos debido a la apropiación progresiva de la gente - que permiten el paseo y el encuentro-, que ordenan cada zona de la ciudad y le dan sentido, que son el ámbito físico de la expresión colectiva y de la diversidad social y cultural.

Sin embargo, el espacio público de la ciudad latinoamericana neoliberal actual supone también privatización y exclusión. La ciudad de Tucumán no ha estado ajena a esta lógica y celebra, en el marco de una agenda municipal vinculada a lógicas urbanísticas compartidas con otras ciudades a nivel nacional, "el primer parque cerrado de la capital". 


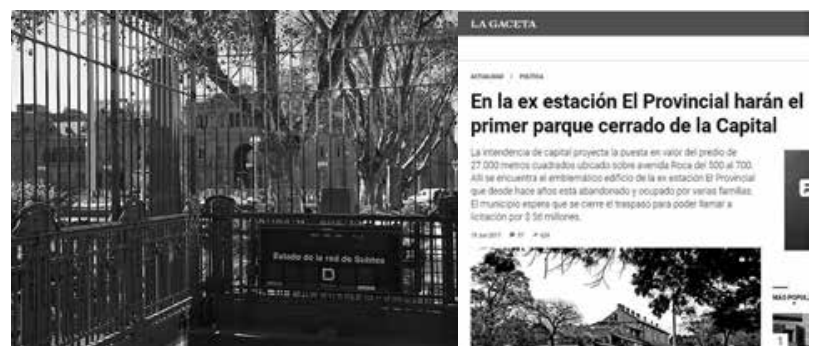

Figura 3. Espacios públicos "cerrados". Fuente: Medios de comunicación nacionales y locales a) Tiempo argentino, 2019 y b) La Gaceta, 2017.

La gestión urbana concentra en los últimos años la inversión en espacios públicos del centro de la ciudad desde una lógica que enfatiza el espacio "cuidado" como espacio "cerrado" y además, en el caso de las calles, "exclusivo" destinado al comercio, reproduciendo la lógica del espacio público de consumo de los shoppings.

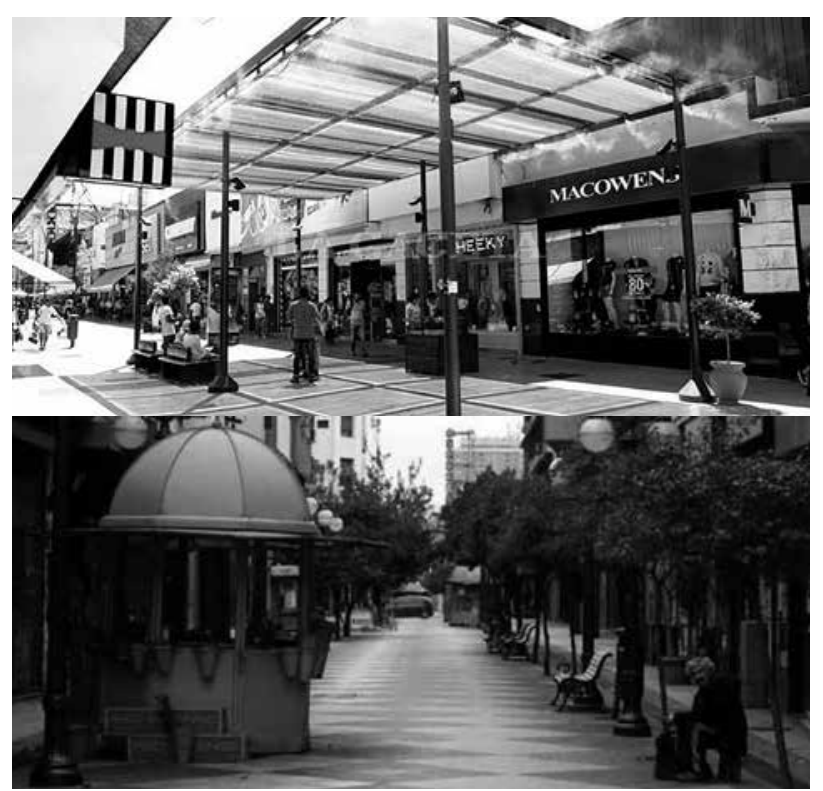

Figura 4. Espacios para el consumo. Transformación del espacio público céntrico Fuente: Fotografías medios locales. a) Tres Líneas, 2016 y b) Contexto, 2019.

Según Ramiro Segura (2014), todo poder busca naturalizar un orden social contingente. En la línea de lo afirmado por Bourdieu (2002), el espacio construido constituye uno de los lugares donde se afirma y ejerce el poder, y en la forma más sutil, el de la violencia simbólica como violencia inadvertida.

La espacialidad es una dimensión esencial en la experiencia del género. Las desigualdades sexuales y de género se expresan -territorialmente- a través de usos diferenciados de los espacios, prácticas desiguales, fragmentación de las relaciones sociales, participación desigual y exclusión física y simbólica. Sin embargo, emergen ante ellas diversas estrategias de apropiación del territorio.

\section{Resultados: la ciudad como espacio público}

Interesa en este apartado dar cuenta de algunos resultados de las experimentaciones a partir de las diferentes iniciativas que articula la línea de investigación/docencia/extensión. Se busca desentrañar el modo en que el espacio urbano legitima una configuración socio-espacial desigual, basada también en el género, para ello se profundiza en las dimensiones simbólica y política.

En particular el "lugar de las mujeres" se ha puesto especialmente en discusión, quizá porque como dice María Ángeles Durán (2008).

el cuerpo, como origen de la percepción, y la percepción y la experiencia como bases del conocimiento, aunque son temas antiguos de la tradición filosófica, interesan en principio más a quienes han sido definidos como cuerpos no principales, no canónicos: como cuerpos no nacidos del barro primigenio, sino del hueso ya formado de la primera y mítica costilla (p. 19).

Del Valle (1997) se refiere a la mujer en el espacio público como "mujer que navega" mientras supone libertad y aprehender lo inabarcable, implica luego volver a "tierra firme", al "espacio privado" (p. 43) ${ }^{17}$.

17 Según Teresa del Valle (1997) se ha elaborado una diferencia entre la pertenencia a un espacio y la situación transitoria. El varón está en lo público y de paso por la casa 


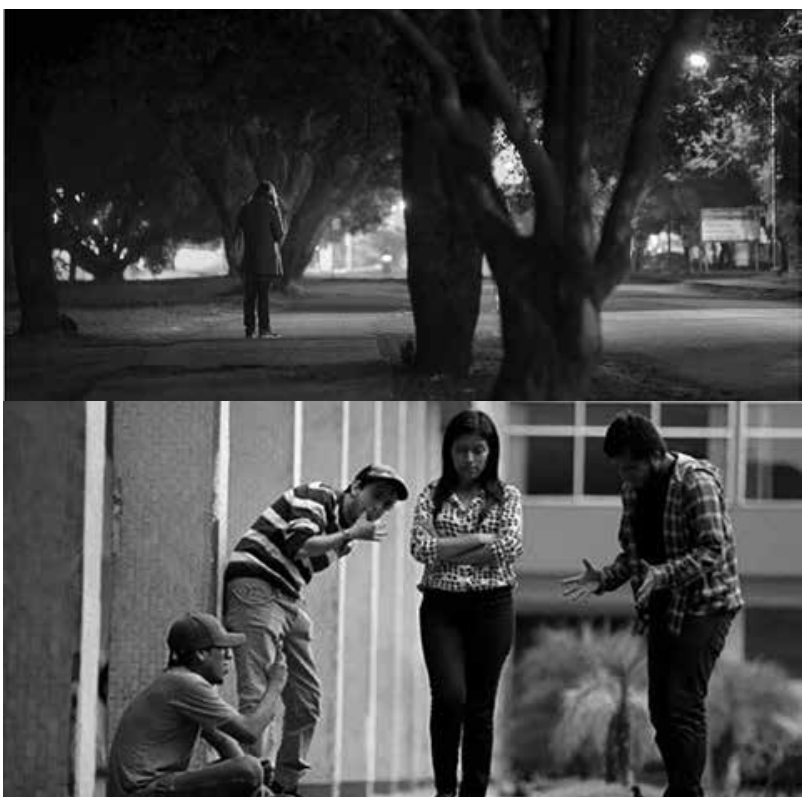

Figura 5. Experiencias de género en la ciudad. Fuente: medios de comunicación locales a) Tres Líneas, 2013; b) Contexto, 2019.

En los relatos de mujeres ${ }^{18}$, las referencias al espacio privado, resguardado, están presentes en casi todas las referencias a los recorridos cotidianos, frente al temor, las inseguridades, al "atravesar" la ciudad. Diversos relatos dan cuenta, además, de cómo las mujeres modifican sus recorridos o sus prácticas en relación a sus vivencias en el uso del espacio público.

Los relatos de las mujeres sobre diversos espacios de la ciudad remiten a experiencias de incomodidad, a veces de temor o naturalización de las estrategias para evitar ciertas situaciones ${ }^{19}$ :

mientras la mujer pertenece a la segunda y transita por lo público. A la vez, "La mujer navega por la ciudad" sería la metáfora que mejor puede explicar el cambio, en tanto una vez que se conocen nuevos espacios, la vuelta puede erigirse en una experiencia renovadora o al menos cuestionadora.

18 En la dinámica participan unas 20 mujeres universitarias de distintas edades, en su mayoría entre 30 y 50 años.

19 Las situaciones descritas fueron relevadas en entrevistas en la vía pública de la ciudad en espacios cercanos a las obras de construcción en las que se realizaba una actividad de sensibilización a empresas constructoras en un programa

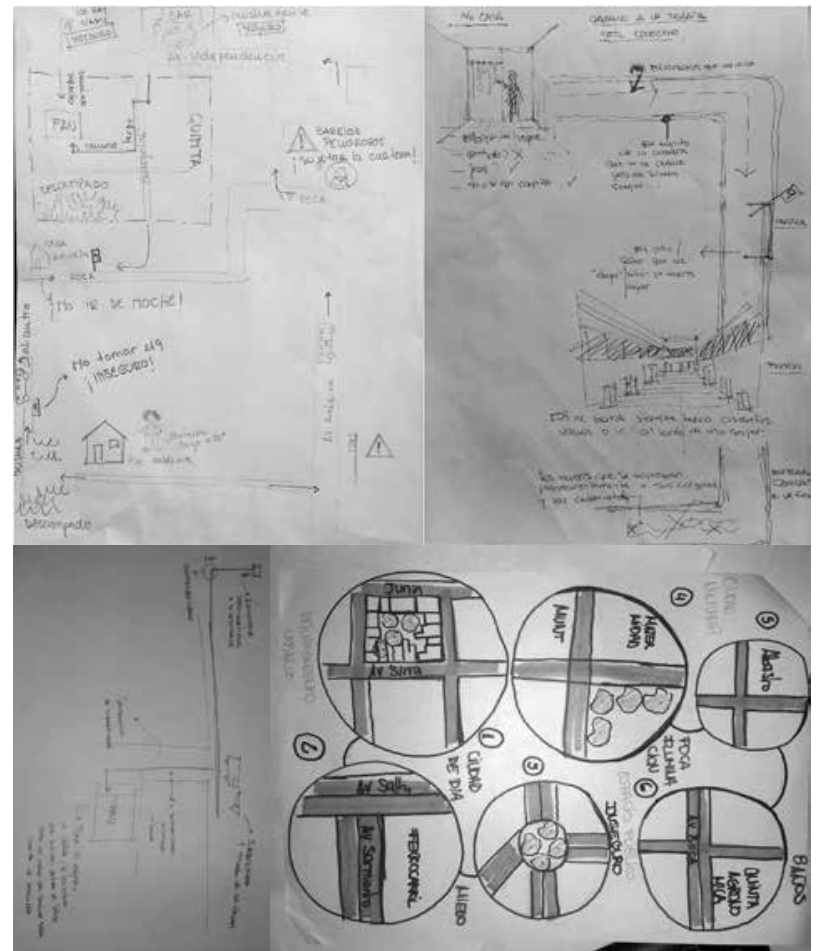

Figura 6. Percepciones y recorridos cotidianos mujeres en el espacio público. Fuente: a,b,c,d Mapas mentales y recorridos cotidianos, Conversatorio Género en la FAU, Laboratorio Género y Urbanismo - OFUT, 2018.

A quien no le dijeron algo en una obra (...) en realidad no es sólo en las obras, sino en la calle (...) claro que es distinto cuando voy con él (su hijo de un año) que cuando voy sola, es como que tienen más respeto (mujer, 25 años)

No me gusta pasar por obras en construcción. A veces uso auriculares para no tener que escuchar lo que me dicen los obreros cuando paso. Evito salir con polleras cortas aun los días que hace calor (mujer, de unos 30 años)

Es feo pasar (por un edificio en construcción), me cruzo a la vereda de en frente. Desde lejos empiezan a mirarme, detienen sus actividades para mirarme pasar (mujer, 22 años)

Vivo en un edificio y en frente hay una obra en construcción. Vivo con las cortinas cerradas ya que cuando salgo al balcón los trabajadores

articulado con la Secretaría de la Mujer "Contra el Acoso Callejero", Febrero 2019. 
de la obra me hablan, me hacen señas, silban. Es incómodo, no puedo hacer nada porque me siento observada. Me encierro (mujer, 27 años) ${ }^{20}$.

Las percepciones de varones fueron diferentes: "nunca me dijeron nada" (transeúnte, varón, 24 años). Por lo general ubican la responsabilidad en las mujeres, en sus prácticas y elecciones: "yo siempre le digo que tenga cuidado con lo que se pone" (obrero, asistente de la capacitación, 45 años), haciendo referencia a otras mujeres de su círculo cercano (esposa e hija).

Las vivencias de la mayoría de las mujeres, reflejan situaciones de "incomodidad" que se encuentran en otros relatos y hace parte de una matriz de comportamiento social.

La sensación de temor de transitar ciertos espacios a determinada hora, el miedo a una persecución, manoseo, acoso, ocurre con mayor frecuencia en las mujeres que en los varones ${ }^{21}$.

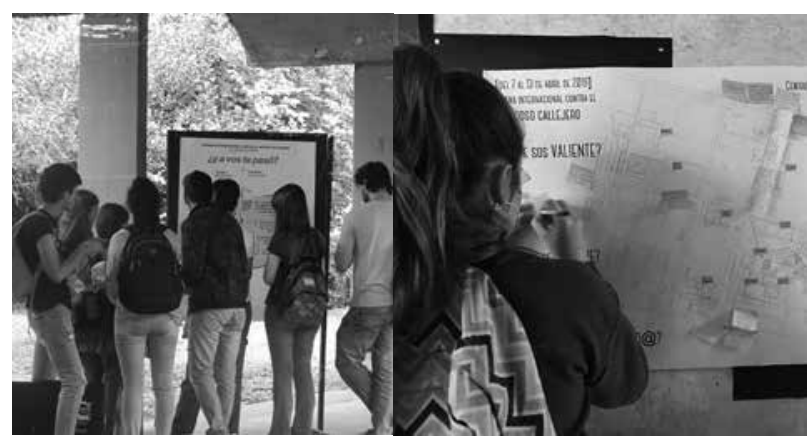

Figura 7. Dispositivos en espacios universitarios. Fuente: elaboración propia, Laboratorio de Género y Urbanismo/ OFUT, 2019. Laboratorio de Género y Urbanismo / OFUT, 2019.

20 Encuestas a transeúntes en la vía pública en ocasión de una capacitación y visita a obra en construcción el marco del Proyecto Género, ciudad y violencias, Laboratorio Género y Urbanismo, OFUT, 2019.

21 A partir de algunos dispositivos de encuesta localizados en la Facultad de Arquitectura y Urbanismo en la Semana Internacional contra el acoso Callejero (mayo, 2019) se registraron mayoría de respuestas de mujeres en relación a la sensación de temor, así como también demarcación de espacios universitarios donde sienten esa sensación.
También se registran manifestaciones alternativas, marginales y hasta subversivas cuando se recogen las interpretaciones de los actores y en las respuestas de la sociedad a esos cambios. Así encontramos en la franja etaria entre 19 y 29 años algunas representaciones sobre una mayor libertad y equidad en el uso del espacio público.

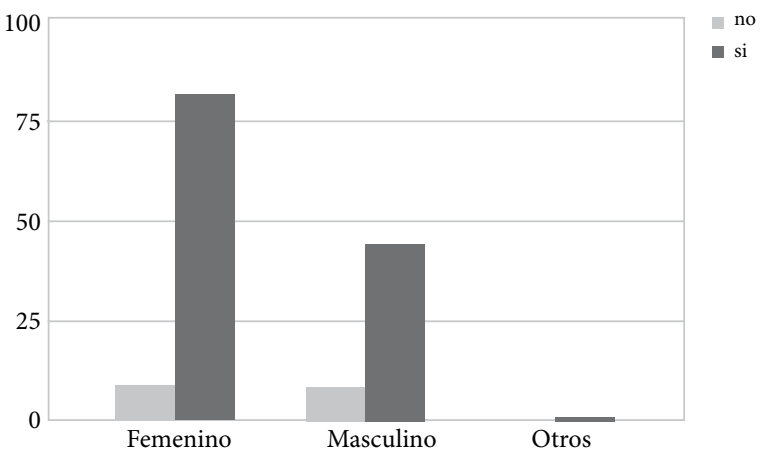

a) Uso de espacios públicos por género

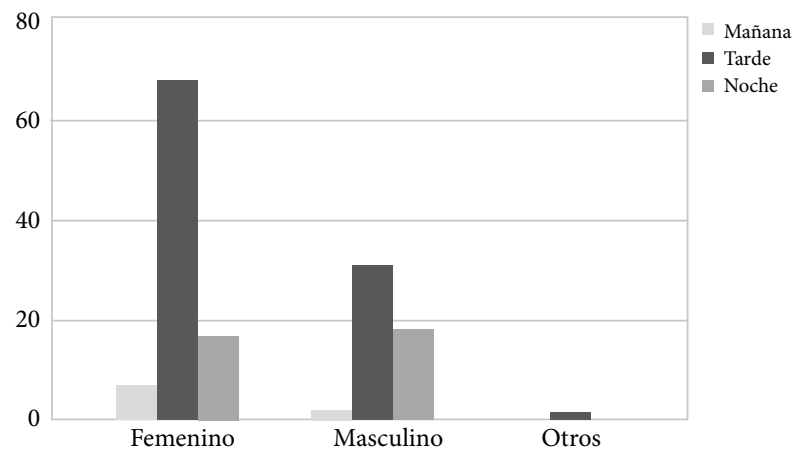

b) Franja horaria de uso de plazas por género

Figura 8. Encuestas jóvenes sobre uso del espacio público. ${ }^{22}$ Fuente: Almará Gussoni (2018) Laboratorio de Género y Urbanismo / OFUT.

Sin embargo, cuando indagamos en las franjas horarias de los usos de esos espacios o en la exposición de motivos por los que no usan los mismos, si encontramos diferencias según género. Las causalidades relacionadas con el miedo, la inseguridad, la incomodidad, son referidas principalmente por las mujeres, tal como se muestra a continuación: ${ }^{22}$

22 Las encuestas fueron realizadas en formato google de manera online a un universo de jóvenes universitarios entre 19 


\begin{tabular}{|l|l|}
\hline \multicolumn{1}{|c|}{ Género femenino } & \multicolumn{1}{|c|}{ Género masculino } \\
\hline "Inseguridad" & $\begin{array}{l}\text { "Porque no" } \\
\text { "Porque no" } \\
\text { "No me hago el tiempo para ir" }\end{array}$ \\
"Prefiero estar en casa a veces y otras no tengo tiempo" & $\begin{array}{l}\text { "Por longo tiempo" } \\
\text { "Seneral nos quedamos en casa }\end{array}$ \\
"Siento que no tengo equipamiento para aprovecharlos" & $\begin{array}{l}\text { y salimos nos vamos al Cadillal o San } \\
\text { Javier" }\end{array}$ \\
"Inseguridad, mal mantenimiento, los jardines de las casas están & "No tienen el equipamiento adecuado" \\
mejor cuidados" & "No me interesan" \\
"No hay muchas actividades para realizar, en general son solo & \\
para sentarse". & \\
"La mayoría del tiempo trabajo" & \\
"Cuando dejé de correr hace unos años fue porque en la plaza a \\
la que iba había una serie de chabones que te gritaban cosas con \\
cada vuelta que daba, al principio no presté atención, pero con el \\
tiempo me cansé y dejé de ir. También andaba en bicicleta hasta \\
que me siguieron también en bici hasta donde debía llegar, me \\
asusté tanto que la bici aún está guardada".
\end{tabular}

Fuente: Almará Gussoni (2018); Laboratorio de Género y Urbanismo / OFUT.

Estas aproximaciones dan cuenta de cómo y de qué forma los mensajes subyacentes en el uso y apropiación de la ciudad constituyen un proceso social que estructura y gestiona atributos de masculinidad y femineidad en el espacio (Bowlby, 1986 en Gonza, 2016).

Por otra parte nos interrogamos acerca de las representaciones sobre las mujeres en el espacio público, sobre los mensajes y símbolos que se utilizan en la ciudad, las prácticas actitudinales y comunicativas que reafirman o se distancian de los estereotipos de identidad y de las jerarquías de género.

En el espacio público de la ciudad de San Miguel de Tucumán, en forma similar a las ciudades descritas por Del Valle (1997) para el caso español, los cascos antiguos cuentan con espacios y zonas referenciales donde tiene lugar una diversidad de actividades sociales. Lo que sucede en esos espa-

y 29 años en el marco de la beca estudiantil Almará Gussoni, 2018. cios se percibe como diferente. Son lugares fáciles de encontrar, bien señalizados, iluminados y sirven de referencia continua.

El callejero es también un marcador temporal con varias dimensiones. El protagonismo de los nombres de las calles, la tienen los varones. Allí aparecen características puntuales de los estereotipos masculinos y femeninos dentro de un sistema de dominación masculina. Así, en la ciudad de San Miguel de Tucumán el 2\% de las calles tiene nombres femeninos, es decir, 9 de 1.123. También ocurre en otras ciudades argentinas, sólo el $3 \%$ de las 2165 calles de la Ciudad de Buenos Aires; esta cifra supera a la de otras ciudades del mundo como, por ejemplo, París que solo tiene el $2,7 \%$ de autovías portadoras de nombres femeninos ${ }^{23}$.

Algunas actividades desarrolladas de participación en procesos de movilización social en torno

23 https://www.nueva-ciudad.com.ar/notas/201703/ 31566-en-la-ciudad-solo-hay-59-calles-con-nombres-demujeres-cuales-son.html 
al 8 de Marzo, permitió considerar por un lado, las violencias que se expresan particularmente sobre el cuerpo de las mujeres y los cuerpos disidentes y por otro, la expresión de sujetos emergentes, en particular del movimiento de mujeres, en el espacio público ${ }^{24}$.

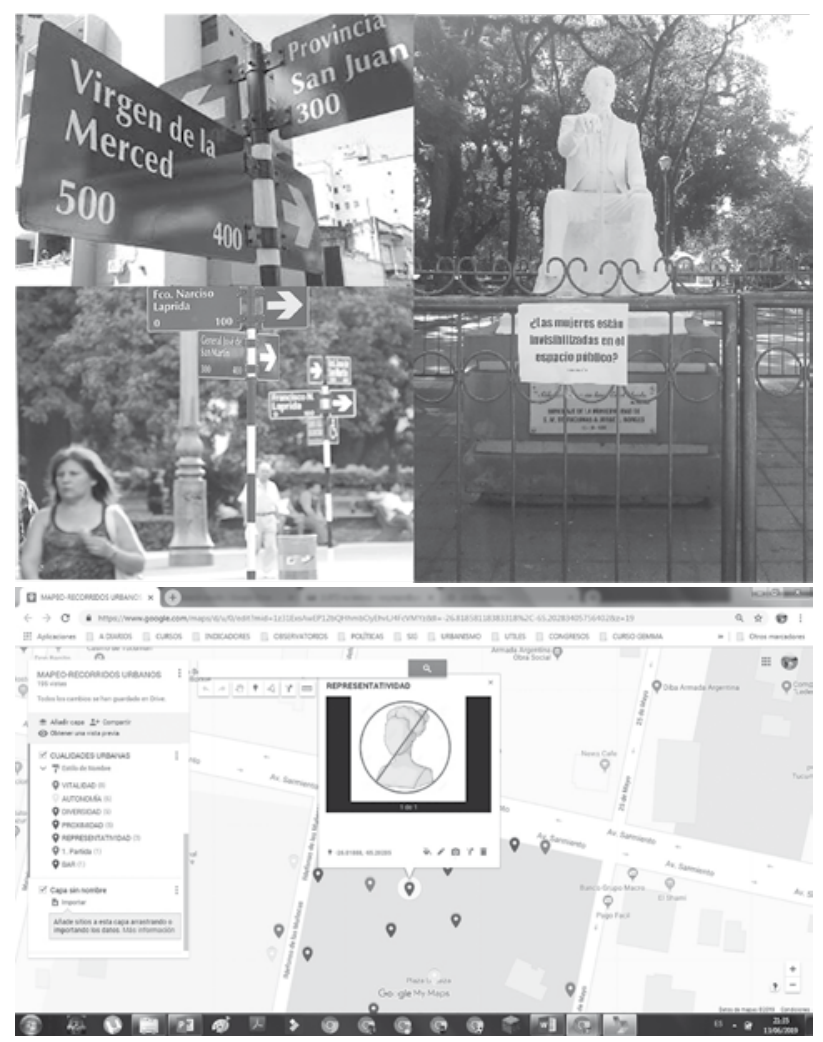

Figura 9. Representatividad en el espacio público. Fuente: registro caminata 7M. Plaza Urquiza. Grimaldos (2019), Laboratorio de Género y Urbanismo / OFUT.

24. Caminata 7M - 2019. En el marco de la actividad 8M del Área de la Mujer y la Comisión de Jóvenes del Colegio de Arquitectos de Tucumán, desde el Observatorio de Fenómenos Urbanos y Territoriales y el Laboratorio de Género y Urbanismo se realizó un itinerario a pie en la Plaza Urquiza (punto de partida de la marcha) con estudiantes y becarias del Laboratorio y OFUT para visibilizar y reflexionar sobre las desigualdades de género en el espacio público. Participaron de esta iniciativa la Secretaría de la Mujer de la Provincia y el Colectivo TreceDiecinueve. Ver: https://www.lagaceta.com. ar/nota/799935/lg-play/que-pasa-cuando-mujeres-salencalle.html.
Las calles con nombres de mujeres refieren en su mayoría a laicas formadoras, santas y vírgenes, mientras que los nombres masculinos remiten a profesionales, artistas, intelectuales, luchadores. Entre algunas últimas modificaciones en el callejero en el municipio de San Miguel de Tucumán se encuentra el cambio de calle Rivadavia a Virgen de la Merced $^{25}$. Ello responde, según Del Valle (1997) a valores que se quieren rescatar por encima de la época a la que pertenecen y tienden a exaltarse a través de personas de clases dominantes.

Existen múltiples formas de violencia. En nuestra sociedad, las violencias se infligen especialmente en los cuerpos de las mujeres, pero también en aquellos cuerpos disidentes de los estereotipos "aceptados". Por otra parte, diversos trabajos señalan que la violencia de género está estrechamente relacionada con cierto tipo de conductas ofensivas permitidas a los varones (e incluso que derivan de la educación inicial de los infantes, y que van orientadas hacia la actividad y agresividad de los niños), mientras que las niñas son educadas mediante condicionamientos que propician su recato y pasividad (Serrano et al, 2009). En el espacio público las representaciones e imágenes de "mujeres objeto" también actúan en el plano simbólico. Ello, junto con las evidencias de las normas de agresividad como cualidades masculinas impuestas, se despliega como formas de exclusión de la participación femenina en el espacio público (Del Valle, 1997).

La ciudad entonces no es neutra, expresa también relaciones de poder y de género. La arquitectura y la planificación de la ciudad y el territorio, así como la calidad de los espacios públicos, influyen directamente en el acceso o exclusión de las personas y a la posibilidad de apropiarse de ellos.

A la vez, el espacio está formado y modelado por procesos ideológicos y políticos; es escenario de conflictos, de constante interacción y lucha entre dominación y resistencia; impone reglas y normas particulares sobre los sujetos pero también es

25 https://www.lagaceta.com.ar/nota/511511/politica/ cambiaron-cartel-rivadavia-virgen-merced.html 


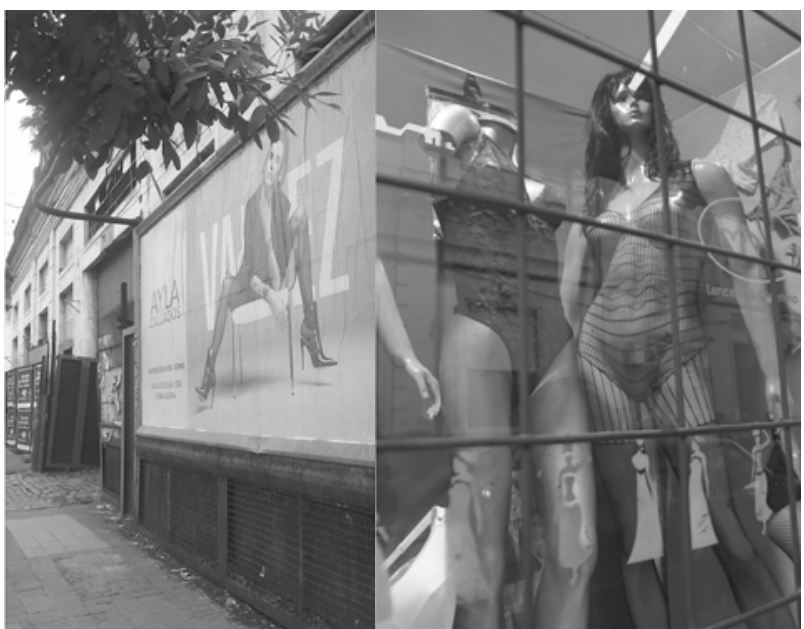

Figura 10. Representaciones e imágenes de mujeres en el espacio público de la ciudad. Fuente: caminata "Registrándonos", $2018^{26}$.

transformado experimentalmente por ellos. Junto a las formas de apropiación hegemónica, existen otras que cuestionan la organización dominante (Lefebvre citado en Sznol, 2007).

Para Moore (citado en Del Valle, 1997), los significados no son inherentes a la organización del espacio sino que a los sujetos les corresponde llenarlos de contenido. En el interés por encontrar las razones de significados alternativos, comprender las formas de delimitación del espacio, entender cómo se crean las barreras y límites físicos y simbólicos mediante la interacción y los cambios que se operan, indagamos en las iniciativas, mayoritariamente producidas por grupos de mujeres, que se articulan con el ánimo de deconstruir los estereotipos de género y que merecen revisarse a la luz de la teoría.

26 La estrategia desarrollada en estas caminatas partió de un trabajo articulado con organizaciones no gubernamentales tales como la Biblioteca Popular Crisálida en dos ediciones del "Registrándonos". Ello en articulación con una tesis doctoral en desarrollo sobre Sexualidades y territorialidades en movimiento. Los primeros resultados de la sistematización de los registros (fotografías, videos, grabaciones de sonido) tienen como objetivo construir una cartografía social que permitan abordar y problematizar los territorios -sociales, subjetivos, geográficos, políticos- e interpretar la realidad urbana de una manera alternativa (López et al, 2018).
A través de pintadas o en actividades puntuales protagonizadas por mujeres o colectivas feministas se "re-semantiza" el espacio público como zonas libres de agresiones para las mujeres, tal como refiere Del Valle (1997). Estos mecanismos introducen variaciones en la apreciación y valoración sobre los espacios.

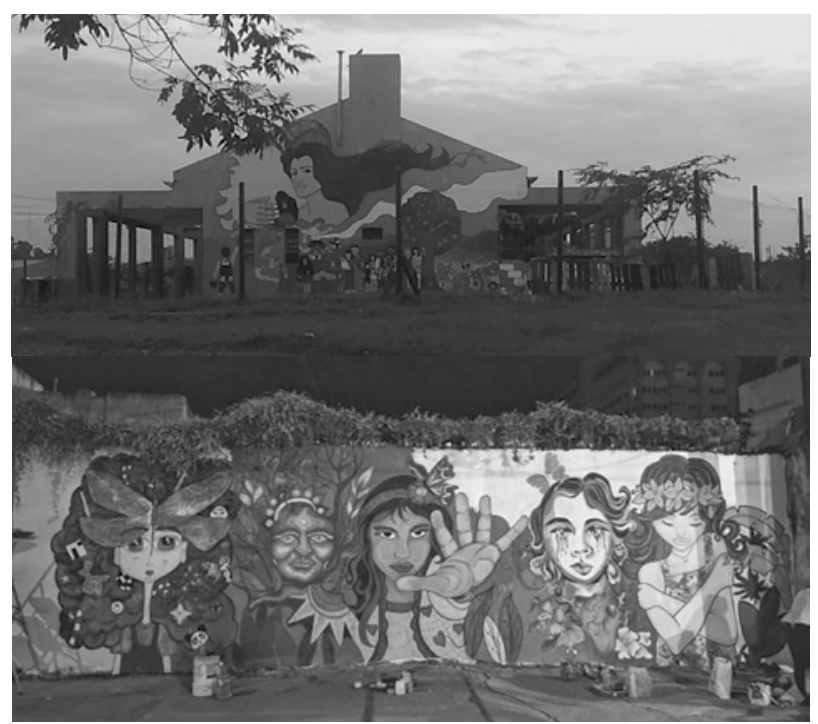

Figura 11. Re-semantización del espacio público. Fuente: a) Fotografía propia, 2019 y b) Mural Calle Cuba (https://muralesbuenosaires.com.ar/2019/05/17/muralninas-no-madres-en-la-ciudad-de-tucuman-en-el-marcodel-dia-internacional-de-la-mujer).

En el período reciente podemos mencionar también acontecimientos políticos y manifestaciones en particular del movimiento de mujeres pero también de otros cuerpos disidentes que se apropian del espacio público de la ciudad en numerosas oportunidades. Marchas y manifestaciones con las consignas "Ni una menos", "8M", "Por el aborto legal, seguro y gratuito", “No más niñas madres”, se desarrollaron principalmente a lo largo del eje de calle 25 de Mayo, desde Plaza Urquiza hacia Plaza Independencia. Ese espacio público, comercial y vinculado al ocio y también espacio político de expresión de numerosos reclamos de diferentes grupos de corte gremial o asociativo, es escenario de las demandas de mujeres y disidencias. 


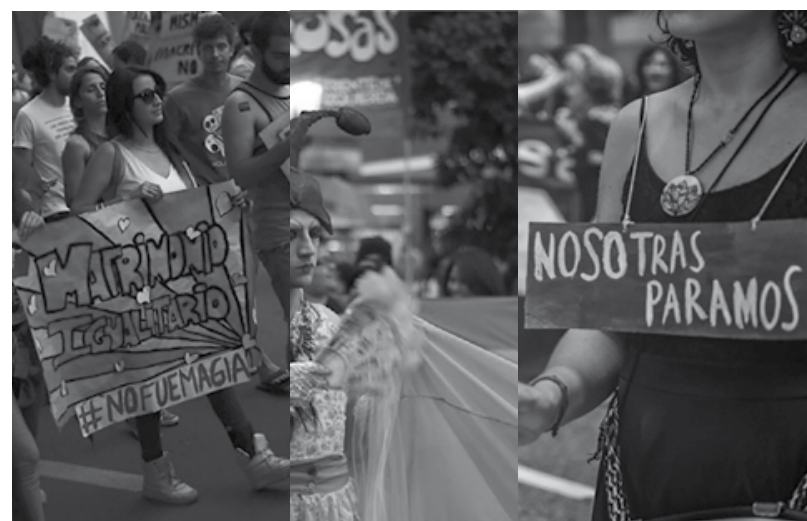

Figura 12. Marchas en el centro de la ciudad de San Miguel de Tucumán. Fuente: López- OFUT (2016) y fotografías de redes sociales.

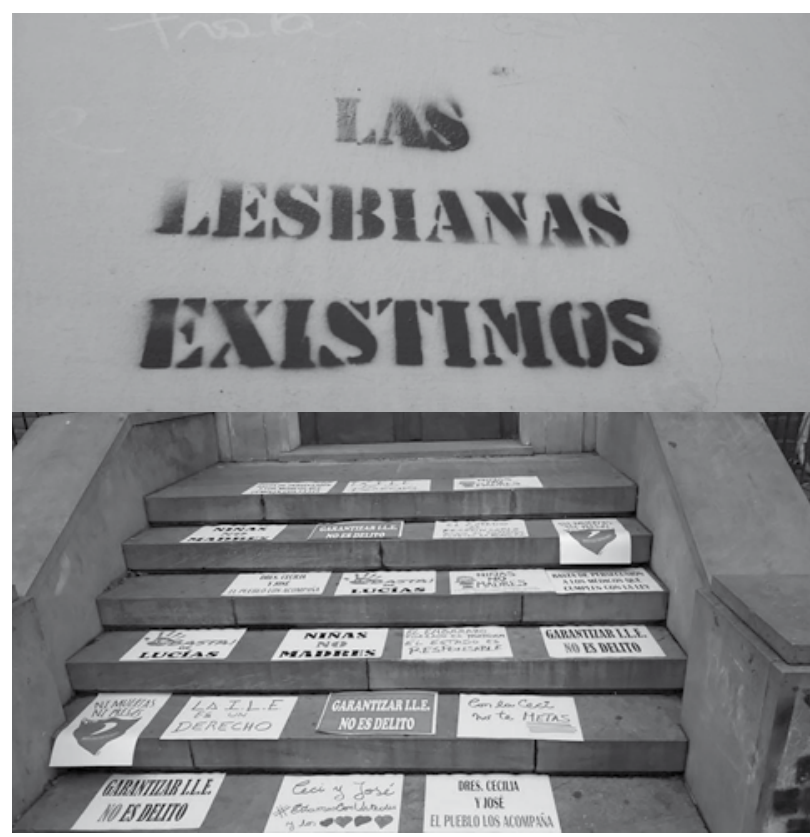

Figura 13. Mensajes en el espacio público. Fuente: caminata "Registrándonos" y fotografía propia (2019).

Los sistemas discursivos, según Sonia Álvarez $(2005)^{27}$, son aquellos que "dan lugar a ciertas organizaciones de conceptos, a ciertos reagrupamientos de objetos, a ciertos tipos de enunciados,

27 Una formación discursiva para Foucault es una regularidad (un orden de correlaciones, posiciones en funcionamiento, transformaciones) dentro de un sistema de enunciados que implica objetos, tipos de enunciación, conceptos, elecciones temáticas (Foucault, 1981, 1992, 1997). que forman según su grado de coherencia, de rigor y de estabilidad, temas o teorías". Podemos reconocer en el espacio público de la ciudad, expresiones y discursos colectivos.

Asimismo, diversas respuestas en materia de política pública, desarrolladas en los últimos tres años también refieren a la visibilización de la temática de la violencia de género, con carteles e iniciativas de comunicación e información sobre los recursos institucionales hacia la generación de espacios libres de violencia.

Una preocupación que atraviesa nuestras indagaciones se refiere al grado en que la distribución espacial y el contenido de las iniciativas existentes consigue tensionar y desandar la histórica dicotomía entre público-varón, privado- mujer. El registro con la cartografía colaborativa es sustantiva.
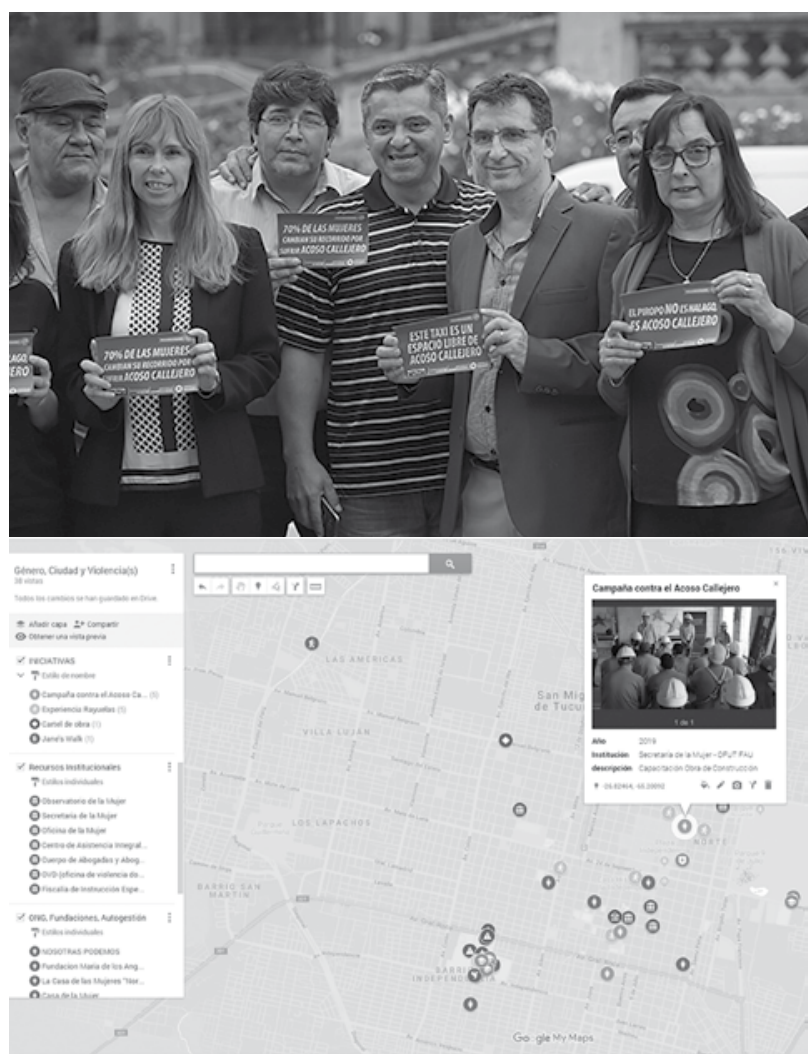

Figura 14. Iniciativas contra el acoso callejero. Fuente: articulación inter-institucional Laboratorio Género y Urbanismo / OFUT y Secretaría de la Mujer, 2019. 
Spain (citada en Del Valle, 1997) se refiere a espacios urbanos de género como aquellos generados por mujeres en la ciudad física y simbólicamente. Se producen cuando se dan algunas condiciones del contexto: desequilibrios en las dinámicas de población, transiciones políticas y/o, incertidumbre respecto a la responsabilidad de los servicios. Todos estos elementos se encuentran latentes en los últimos años: ciudades con menor fertilidad y mayor envejecimiento, cambios de gobierno, interpelación de bienes y servicios con eje en el cuidado ante la sostenida participación femenina en la esfera laboral o comunitaria.

Según Teresa del Valle (1997) la acción de estar en un espacio, aunque fuera de forma pasajera y coyuntural produce cambios en relación al contexto sociocultural. Se refiere a los espacios puente, como aquellos que ofrecen características diferenciadas de los espacios interiores, exteriores y públicos. Los mismos tendrían cierto anclaje en los interiores y en los públicos, pero su objetivo principal está en ser apoyaduras del cambio; y desaparecerían una vez que se hayan cumplido sus objetivos. Mientras que los espacios interiores y los públicos pueden actuar como referencias estables, se atribuye a los espacios puente la característica de circunstanciales. En ese sentido entonces $-y$ siguiendo con la autora mencionada- se trata de pensar la ciudad de una forma nueva teniendo en cuenta los conceptos de i) conservación, ii) transformación y iii) creación. La conservación implica prolongar la función de un espacio, su sentido. La transformación es la intervención de algo mediante la continuidad y la mejora. La creación tiene características de más atrevida y generativa.

La visión de la ciudad debe considerar la relación espacial de los colectivos, su novedad y creatividad. Prestar atención a las actividades y sus manifestaciones en el espacio público, a las creaciones temporales de espacios, identificar las redes espaciales en la ciudad, en particular de los grupos de mujeres, conceptualizar a las mujeres en la ciudad en espacios concretos, asociaciones, reconociendo nuevas formas de tejido social.

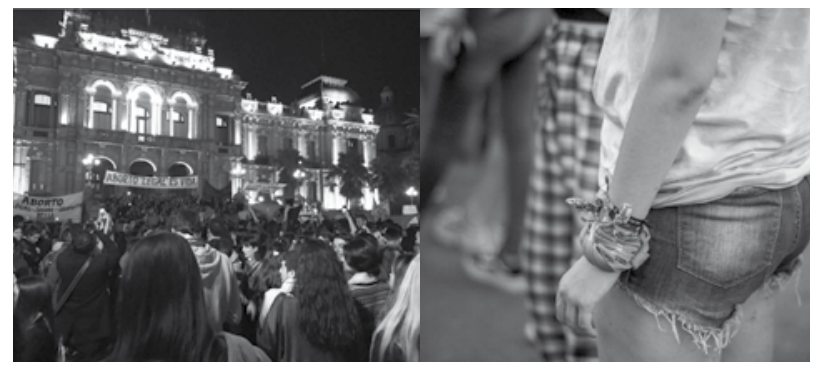

Figura 15. Marchas por el aborto legal en Tucumán, año 2019. Fuente: medios locales La Palta y Prensa Obrera

\section{Reflexiones finales.} Territorialidades emergentes y desafíos de la universidad a una nueva lectura de la ciudad desde la mirada de género

Los procesos sobre los que da cuenta este artículo interpelan la ciudad futura. Son innovadores en tanto constituyen nuevas referencias y rupturas con lo existente, punto de partida de transformaciones y creaciones. Las experiencias mencionadas implican espacios y atribuciones nuevas que a través de acciones concretas reciben significados nuevos, muchas veces subversivos, modos de organización de inconformismo y rebeldía, aportes e innovaciones para el desarrollo personal y social. Las acciones colectivas logran construir nuevas formas de organización del espacio, nuevas formas de territorialidad, en tanto desafían las actuales estructuras de dominación.

En ese contexto, el campo del ejercicio profesional de la arquitectura y el urbanismo también se ve interpelado. Ámbito tradicionalmente masculino, a pesar de la mayor incidencia reciente y creciente de profesionales mujeres, no ha estado exento de contradicciones y tensiones. La pregunta que situaba ya Dolores Hayden (1982) a fines de siglo XX sobre la importancia del estudio sobre cómo se elaboran las construcciones resultantes desde el espacio o en relación a éste y el modo en que inciden directa o indirectamente en el diseño y 
mantenimiento de las relaciones de género, se resitúa como una pregunta desafiante.

A pesar de que el espacio público de las ciudades refuerza los procesos de jerarquización asociados a los sistemas de género y la construcción del espacio urbano está más orientado a mantener a las mujeres en ciertos espacios desde lo material o simbólico, desde la dimensión política, las iniciativas de cambio y transformación y de apropiación del espacio público y construcción de territorialidades emergentes.

Los resultados referidos ponen de manifiesto, desde la experiencia del laboratorio, la construcción de conocimiento como una forma de militancia. Se asumen los estudios feministas como una estrategia fundamental para fomentar la producción de saberes desde la perspectiva de las mujeres transformando los modos tradicionales de construcción de conocimiento.

Las iniciativas de cambio y transformación de las que da cuenta este trabajo se producen como manifestación colectiva de las estructuras profundas y generan nuevas referencias en la urbe y da voz al "grupo mudo" frente al dominante que demanda ser comprendido y transmitido también en el ámbito científico y académico. En esa línea, el estudio de la(s) violencia(s), el género y la ciudad responde a la necesidad de la construcción de nuevos paradigmas interpretativos para este cambio de época y las nuevas orientaciones del desarrollo urbano.

La perspectiva de género tiene un valor político y teórico. Político, por la capacidad de transformar y teórico, por la necesidad de construir argumentos y conocimientos para impulsar esa acción política necesaria. Le cabe a la universidad un rol indiscutible en este sentido, comprometida con sus integrantes y su tiempo. Si bien se ha avanzado en la generación de espacios de género en dicho ámbito todavía sigue siendo un enorme desafío transversalizar las currículos y los programas universitarios para lo cual se requiere la construcción de conocimiento sustantivo.
La ciudad futura dependerá de cómo se confronten las dinámicas negativas y positivas que están implícitas en el desarrollo urbano, con incidencia determinante de los actores de las políticas públicas y la fuerza de las demandas ciudadanas, en la articulación de los procesos de movilización social, política pública y reflexión intelectual.

\section{Referencias bibliográficas}

Álvarez, S. (comp.) (2005). Trabajo y producción de la pobreza en Latinoamérica y el Caribe: Estructuras, discursos y actores. Buenos Aires: CLACSO.

CEPAL (2016). Estrategia de Montevideo para la implementación de la Agenda Regional de Género en el Marco del Desarrollo Sostenible hacia 2030. XIII Conferencia Regional sobre la Mujer de Améerica Latina y el Caribe. Montevideo: Acnur.

Cuenya, B. (2012). Cómo hacer de la ciudad una ecuación posible: Las visiones de Daivd Harvey y Jordi Borja sobre el derecho a la ciudad. Revista Café de las Ciudades. Disponible en: [http://www.cafedelasciudades.com.ar/politica_120.htm].

Czytajlo, N. (2013). Espacio, género y pobreza. Discursos, prácticas y subjetividades. Políticas sociohabitacionales en Tucumán (2004-2008). Cuadernos de Investigación Urbanística, 6 (90): pp. 1-87. Disponible en: [http://polired.upm.es/ index.php/ciur/article/view/2098/2174].

Czytajlo, N. (2017). Desigualdades socio-territoriales y de género en espacios metropolitanos. Bitácora Urbano Territorial, 27, 3, pp. 121-134. Disponible en: [https://revistas.unal.edu.co/ index.php/bita cora/article/view/66484].

Del Valle, T. (1997). Andamios para una nueva ciudad. Lecturas desde la antropología. Madrid: Cátedra.

Di Lullo, R. (2009). El espacio público urbano. Consideraciones y actuaciones. San Miguel de Tucumán: EDUNT. 
Durán, M. (2008). La ciudad compartida: conocimiento, afecto y uso. Santiago de Chile: Ediciones SUR.

Falú, A. y Segovia, O. (2007). Ciudades para convivir: sin violencias hacia las mujeres. Debates para la construcción de propuestas. Santiago de Chile: Ediciones SUR.

Gonza, C. N. ( 2016) Geografía de género. Grafitis y mujeres anónimas en el espacio público. Revista Question, No. 49.

Hayden, D. (1982). The Grand Domestic Revolution: A History of Feminist Designs for American Homes, Neighborhoods, and Cities. London: The MIT Press.

ILPES, CEPAL (2016). Manuales de la CEPAL $N^{\circ}$ 4. Territorio e igualdad: planificación del desarrollo con perspectivas de género. Santiago de Chile: CEPAL.

López, J., Czytajlo, N., Paz, R. y Díaz Fernández, G. (2018). Experiencia Institucional y/o Social: Registrándonos. En: Primera Jornada Regional sobre acceso a la justicia y derechos humanos en el Noa. Argentina: Facultad de Derecho y Ciencias Sociales.

McDowell, L. (2000). Género, identidad y lugar. Valencia: Cátedra.

Peña Molina, B. (1998). Apuntes para una metodología en el estudio del binomio género y espacio urbano. Boletín electrónico $C F+S$. México. Disponible en: [http: //habitat.aq.upm.es/boletin/n7/ abpen.html]. [consultado: Septiembre de 2003].

Peker, L. (2019). La revolución de las hijas. Buenos Aires: Paidós.

Romero, J. (2004). Geografía Humana. Procesos, riesgos e incertidumbres en un mundo globalizado. Barcelona: Ariel.

Segato, R. (2018). Contra-pedagogías de la crueldad. Buenos aires: Prometeo.

Segura, R. (2014). Desigualdad social y espacio urbano. Reflexiones sobre naturalización, legitimación y reproducción de las desigualdades en el espacio urbano. XI Congreso Argentino de Antropología Social, Rosario.

Serrano, H., Zarza, M. P., Serrano, C., Gómez, B. y Iduarte, J. (2011). Códigos visuales de género y configuraciones sexuales evidenciadas en la fotografía. Revista Latinoamericana de Ciencias Sociales, Niñez y Juventud, 2(9), pp. 769-782. Disponible en: [http://www.scielo.org.co/pdf/ rlcs/v9n2/v9n2a19.pdf.]

Sznol, F. E. (2007) Geografía de la Resistencia. Protesta social, formas de apropiación y transformación del espacio urbano en la Argentina (1996-2006) Revista Theomai, $1^{\circ}$ semestre. [on line]. Disponible en: [http://www.revistatheomai. unq.edu.ar/numero15/ArtSznol.pdf]. 